\title{
First Miscellany Issue
}

Objectivizing the Editorial Process from Review Stage to Publication

Premier numéro varia. Éléments pour une objectivation du processus

d'évaluation-publication

Julienne Flory

Translator. Delaina Haslam

\section{(2) OpenEdition}

Journals

Electronic version

URL: https://journals.openedition.org/bssg/610

DOI: $10.4000 /$ bssg.610

ISSN: 2490-9424

Publisher

Presses universitaires de Vincennes

\section{Electronic reference}

Julienne Flory, "First Miscellany Issue", Biens Symboliques / Symbolic Goods [Online], 8 | 2021, Online since 20 May 2021, connection on 23 July 2021. URL: http://journals.openedition.org/bssg/610 ; DOI: https://doi.org/10.4000/bssg.610

This text was automatically generated on 23 July 2021.

Biens Symboliques / Symbolic Goods 


\section{First Miscellany Issue}

Objectivizing the Editorial Process from Review Stage to Publication

Premier numéro varia. Éléments pour une objectivation du processus

d'évaluation-publication

\section{Julienne Flory}

Translation : Delaina Haslam

Fig.1. Textile with Animals, Birds, and Flowers

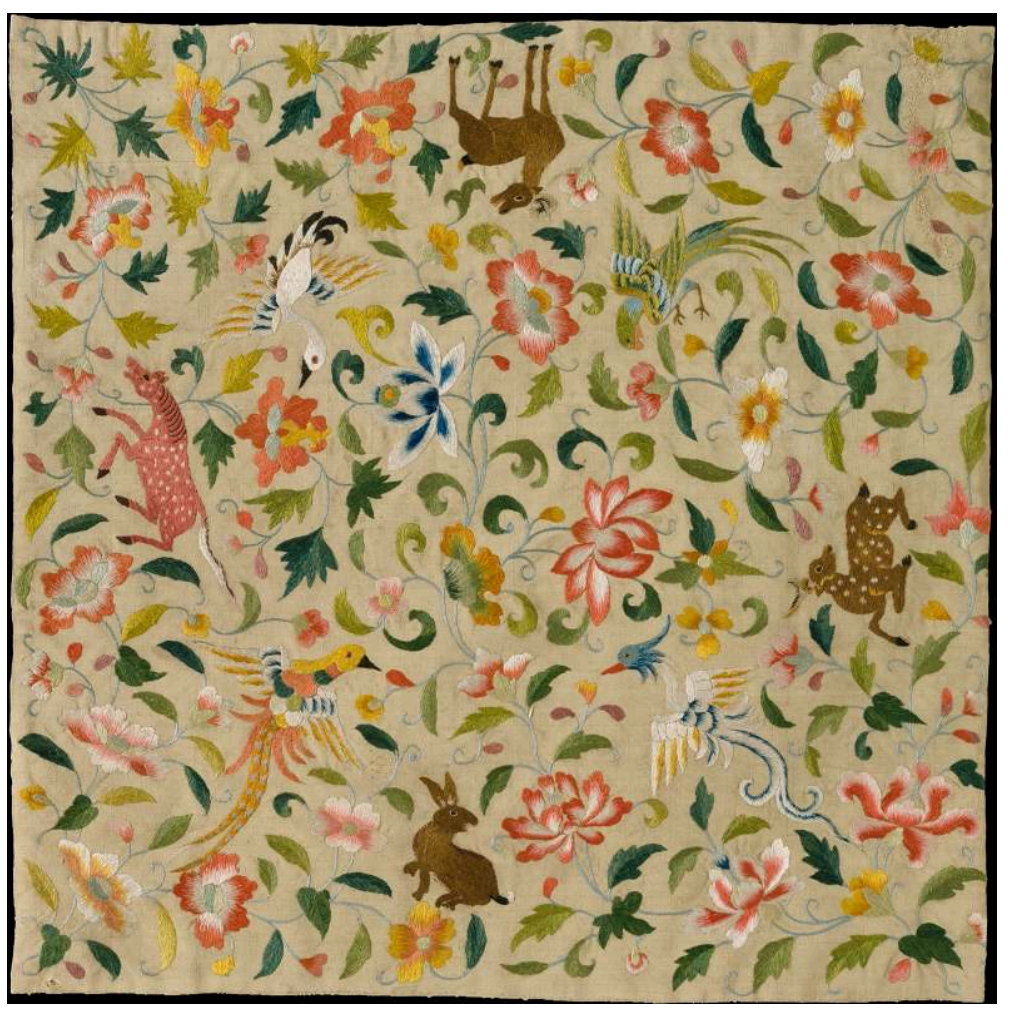

This textile demonstrates the longevity of motifs in eastern Central Asia. Late 12th-14th century (c) The MET collection d'art 
1 Biens symboliques/Symbolic Goods (BS/SG) issue number 8 is the first issue comprising peer-reviewed accepted papers, submitted outside of a thematic issue. This miscellany issue provides an opportunity for us to review articles received and published since 2017, and explain the process that articles undergo before publication.

2 Since the launch of the journal, the editorial team has strived to meet the requirements of the Committee on Publication Ethics ( $\left.\mathrm{COPE}^{1}\right)$ with the aim of ethical publication of open science. We wish to reveal, as transparently as possible, the publication process and the work of the editorial team and external experts - who are sometimes precarious workers of the higher education and research system - who devote their time to ensuring the journal's existence.

\section{The Review Process}

3 The review process described below also relates to miscellany articles that have been published as a supplement to issues of the journal, as well as to those resulting from a call for papers in the context of a thematic issue.

\subsection{From Reception of Articles to "First Read"}

4 The editorial board aims to support authors as fairly as possible by working with them to improve proposed articles. The way in which articles are reviewed has thus evolved since the journal was founded, going from a double review (by one internal and one external reviewer) to a triple one, with two internal and one external reviewer. This shift to two internal peer reviews requires a longer time frame, but allows for more discussion of the articles by the editorial board, and provides authors with maximum guidance in making their articles clearer and more effective, with the peer review form having been modified to this effect. While it should be evident, it is undoubtedly useful to remind ourselves - particularly at this moment - that publishing quality articles takes time.

5 An article received by the journal is first of all read by someone on the editorial board chosen in alphabetical order who must decide if the article will be put forward for peer review; that is to say whether or not it clearly meets the minimum scientific requirements set out by the journal, and whether it fits the scope of its theme ${ }^{2}$. The members of the board are given a form to help with this process (see Appendix). Rejected articles may be accompanied by suggestions for improvement and an invitation to resubmit the text after reworking. Indeed, even in cases where an article is rejected at this first-read stage, it will still usually have been seen by several editorial board members, allowing it to gather different opinions to better orientate revision and resubmission.

\subsection{From Review to Publication}

6 Following the first-read stage, the article is submitted for peer review. The board member who carried out the first read also carries out the first internal peer review, while the editorial team designates a second internal and an external reviewer ${ }^{3}$ according to the subject matter and discipline of the article. Of the three people 
involved in the peer review of an article, one is usually unfamiliar with the subject matter so as to assess the accessibility of the text for a non-specialist readership. BS/SG is a scientific journal that is intended to be readable and understandable to a broad academic readership (international, student, etc.) and to professionals in education, the media, and in the cultural industries who may be interested in its themes. The two other - internal or external - readers of the article are specialists in the subject matter. We should note that it is not uncommon to have to contact two or even three people in succession in the process of securing the external peer review of an article since the chronically overloaded timetable of researchers and student researchers often prevents them from taking on the detailed review of an article and writing up a report - an important task that requires the utmost rigour and can sometimes take several days - usually with a six-week deadline.

7 A review form accompanies the article sent to the experts in French or English depending on the language of the article. The reviews received are then sent to the author, sometimes completed by a synthesis of these reviews, written by the internal experts following discussion of the article by the editorial board [EB]. On the form sent to the experts, there are four possible options: the article may be accepted in its current state; accepted with minor changes; rejected; or major changes can be requested before the EB decides on publication. If the three experts disagree on the final opinion, the article is read and discussed by the entire EB.

8 The author is then expected to provide a second version (V2), taking into account suggestions made in the reviews. This V2 is reviewed by internal experts and sometimes also by the external expert, depending on the extent of the changes requested. After these reviews have been carried out, if the article is still not deemed "publishable" as is, a third version can again be requested, with suggestions and proposals by internal experts, and so on. Once accepted for publication, the article is finally reviewed by one of the two internal experts for a specific review we call "pretranslation." In this final review we check not only that the language is free from elaborate syntactical twists (embedded relative clauses, double negations, etc.) - which are potential sources of error at the translation stage - but also that the text is directly intelligible to a non-French and/or non-French-speaking readership. This may involve spelling out acronyms ("CNRS"/Centre national de la recherche scientifique), for example, or else clarifying the name of French institutions that may not be recognisable to a foreign readership even if they are French-speaking using a footnote ( for école maternelle, BTS, ENS, for example $e^{4}$. The same is true of expressions that refer to French domestic politics (for example, "the Lang years"5), or national acronyms such as "Smic" 6 or "CRS"? This stage, which is crucial in order to make articles clearer and avoid errors and misunderstandings as far as possible when switching to English, is also anticipated on the internal peer review form to draw the attention of the internal experts and authors to the article's forthcoming translation as early as the editing stage. The article is then ready to be sent for translation.

9 Having explained the process followed for all articles submitted to the journal, let us now look at the objective data specifically for articles submitted outside of a thematic issue. 


\section{Articles Submitted Outside of a Thematic Issue (Miscellany)}

10 The EB received three unsolicited articles as soon as the summer 2017, that is even before the journal published its first issue, in October of the same year. These were three articles written by French researchers, demonstrating how well the news of a new journal had spread by word-of-mouth in the humanities and social science milieu. From the first issue (October 2017) to writing this editorial (November 2020), the journal has received thirty-five articles for miscellany publication: five in 2017; eleven in 2018; eleven in 2019; and eight between January and November 2020.

\subsection{The Authors}

11 The majority of the articles received were written by men (nineteen out of thirty-five); two were written jointly by men and women; and fourteen were written by women only. In addition, the journal received more articles from authors who were then precarious workers (graduate/doctoral students or scholars without a teaching or research position) (60\%) whose dynamism is actually greatly beneficial to the world of higher education and research, as well as to journals, conferences and congresses 8 . Indeed, it may have seemed that a new journal could be more accessible to young scholars than more "established" ones. We should also note that of the articles written by staff with stable job in higher education and research, more were by men (64\%) than by women (36\%); this gap reduced between authors without stable job in HE (43\% women and $52 \%$ men).

Fig. 2. Gender and Status of Authors of Unthematic Articles Received

\begin{tabular}{|c|c|c|c|c|c|c|c|c|}
\hline \multirow[b]{2}{*}{ Status } & \multicolumn{2}{|l|}{ Female } & \multicolumn{2}{|c|}{$\begin{array}{l}\text { Female and } \\
\text { Male }\end{array}$} & \multicolumn{2}{|l|}{ Male } & \multicolumn{2}{|l|}{ Total } \\
\hline & Number & $\%$ & Number & $\%$ & Number & $\%$ & Number & $\%$ \\
\hline Without stable job in $\mathrm{HE}$ & 9 & $43 \%$ & 1 & $5 \%$ & 11 & $52 \%$ & 21 & $100 \%$ \\
\hline With stable job in HE & 4 & $36 \%$ & & $0 \%$ & 7 & $64 \%$ & 11 & $100 \%$ \\
\hline $\begin{array}{l}\text { With and Without stable job in } \\
\text { HE }\end{array}$ & 1 & $33 \%$ & 1 & $33 \%$ & 1 & $33 \%$ & 3 & $100 \%$ \\
\hline Total & 14 & $40 \%$ & 2 & $6 \%$ & 19 & $54 \%$ & 35 & $100 \%$ \\
\hline
\end{tabular}

Source: Julienne Flory for BS/SG

12 Compared with the articles submitted for a thematic issue, that is to say those commissioned by the editors or received in response to a call for papers and published between November 2017 and November 2020 - thirty-nine articles in total - unsolicited submissions of articles to the journal appear less favourable in terms of equality. Indeed, $49 \%$ of articles in the issues were written by one or more women, $38 \%$ were written by one or more men, and $13 \%$ were written by authors of both genders. We 
might be tempted to analyse these data through the lens of knowledge established in gender studies, and to thus consider that men - being more inclined by their socialization to display "confidence" - may be more willing to send unsolicited articles to A journal. This situation may also be explained by the extra time that male scholars engaged in a heterosexual couple can have, since their partner is generally the one who takes on both the housework and the mental load associated with it (Devineau, Couvry, Feliu, Renard 2020). Indeed it is foreseeable that, in the coming months, this gap between male and female authors will widen as a result of the spring 2020 lockdown restrictions, which, on account of the closure of nurseries and schools in particular, increased women's workload (Confinée Libérée 2020).

\subsection{An International Outlook}

One of BS/SG's defining editorial features - the systematic publication of articles in two languages, French and English - is likely to be a major motivating factor for authors submitting to the journal since the globalization of scientific productions and the strong incentive to internationalize academic careers increasingly persuades authors to publish their articles in English.

14 As long as we can ensure (and afford) it, the practice of translation is key to the journal: the editorial board has been working in this way for three years with an exceptional team of professional translators (five women and one man) who specialize in humanities and social science ${ }^{9}$. After translation, the English versions are proofread by a native English translator while the articles are also read simultaneously by the editorial team to ensure harmony between the two language versions. Finally, since translating a text into English does not guarantee that it will be read internationally, the English versions of our articles are then subject to a targeted send-out to nonFrench-speaking colleagues who work within the scope of the articles' themes. This management of translations and their circulation among non-French-speaking researchers is something that makes the journal unique ${ }^{10}$.

Thus, thanks to the attention paid to translations and their targeted dissemination, BS/ SG has attracted non-French-speaking readers and authors in the last few years. In fact, almost $30 \%$ of the articles submitted outside a thematic issue come from outside France, and 23\% were written originally in English. Beyond Europe, articles have arrived from Canada, Argentina, and Brazil.

Fig. 3. Geographical Origin of Items Received

\begin{tabular}{|l|l|l|}
\hline Country of Origin & Number & $\%$ \\
\hline Argentina & 2 & $6 \%$ \\
\hline Belgium & 2 & $6 \%$ \\
\hline Brazil & 1 & $3 \%$ \\
\hline Canada & 1 & $3 \%$ \\
\hline France & 25 & $71 \%$ \\
\hline
\end{tabular}




\begin{tabular}{|l|l|l|}
\hline The Netherlands & 2 & $6 \%$ \\
\hline UK & 2 & $6 \%$ \\
\hline Total & 35 & $100 \%$ \\
\hline
\end{tabular}

Source: Julienne Flory for BS/SG

\section{Published and Rejected Articles}

Biens symboliques/Symbolic Goods published its first miscellany article as part of its second issue in spring 2018. This article is fairly representative of those which followed in this section up until April 2021: a text written by a man without tenure at the time of submission (he gained it two years later - we wish a similar fate on all authors of miscellany papers in the same situation.)

\subsection{Published Articles}

Eight unsolicited articles have been published to date (representing $23 \%$ of those received). At the moment of collecting the data, nine articles (26\%) are at peer review phase (9\% at "first read" and $17 \%$ at peer review), and thirteen articles (37\%) have been rejected (26\% after "first read" and $11 \%$ after peer review.)

Fig. 4. Status of Articles At Time of Data Collection

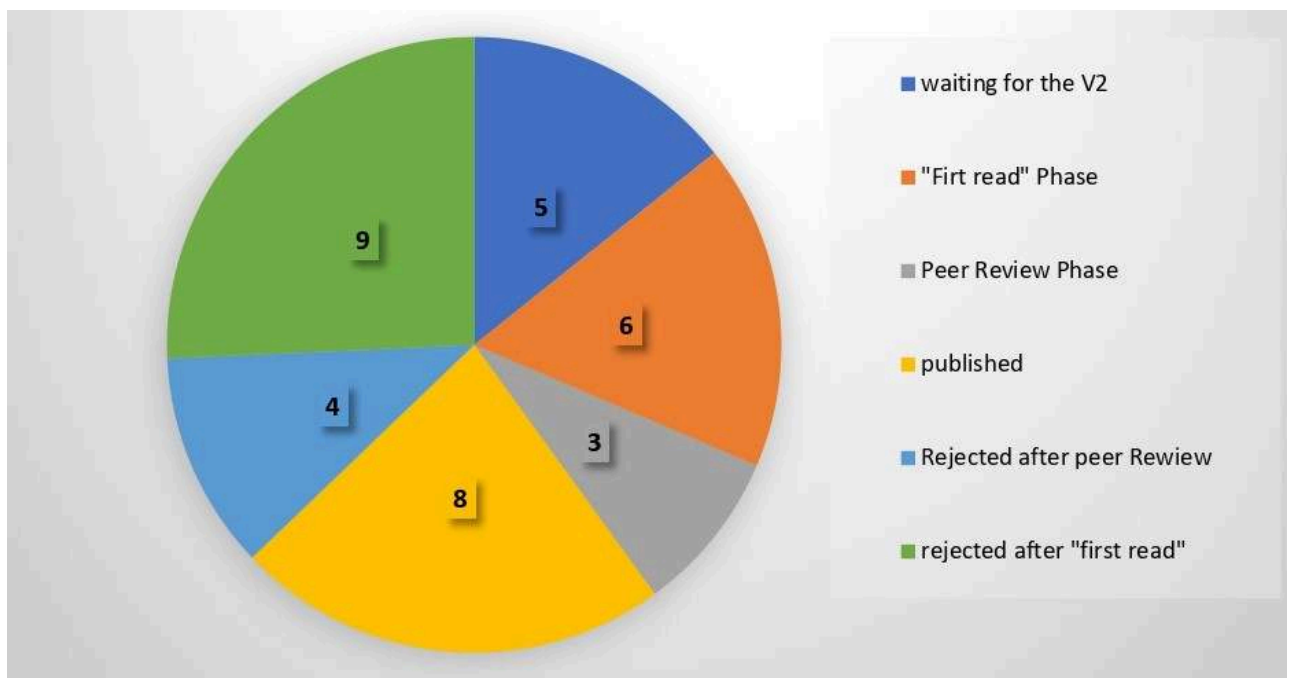

Values represent number of articles

Source: Julienne Flory for BS/SG

Half of miscellany articles published were written by two people, while only $17 \%$ of all miscellany articles received were written by more than one person. These articles often result from conversations at conferences and have therefore benefited from scientific discussion before being submitted to the journal, which probably facilitates their publication. Furthermore, collaborative writing also promotes a certain amount of self- 
correction and intensive editing before the article is sent, which tends to facilitate the peer review phase and acceptance of the article by the journal.

Fifty per cent of miscellany articles published in the journal have been written by precarious workers of the higher education and research system, whereas this is the case for only $26 \%$ of the articles published in thematic issues. This can primarily be explained by the fact that - since most of the coordinators have a stable teaching or research position (all five thematic issues published by the journal so far were coordinated by academics with a stable job, in association with colleagues without a stable job for two of them) - it is undoubtedly easier for them to ask their peers to contribute to their dossier. This aspect will be carefully considered by the editorial team to ensure greater equity and better access for authors without tenure in future issues of the journal.

Fig. 5. Gender and Status of Authors of Published Articles

\begin{tabular}{|c|c|c|c|c|c|}
\hline & \multicolumn{5}{|c|}{ Articles written by } \\
\hline & Number & $\%$ & & Number & $\%$ \\
\hline Women & 1 & $13 \%$ & Without Tenure & 4 & $50 \%$ \\
\hline Women and Men & 1 & $13 \%$ & With Tenure & 2 & $25 \%$ \\
\hline Men & 6 & $75 \%$ & With and Without Tenure & 2 & $25 \%$ \\
\hline Total & 8 & $100 \%$ & Total & 8 & $100 \%$ \\
\hline
\end{tabular}

Source: Julienne Flory for BS/SG

\subsection{Interdisciplinarity}

As stated on the website, Biens symboliques/Symbolic Goods is a peer-reviewed, bilingual, interdisciplinary, and international journal." Interdisciplinarity is clearly not a hollow slogan for authors insofar as the unsolicited articles sent in come from different disciplines: while the majority of them are on sociology and political science (64\%), the journal has received articles on aesthetics, history, history of art, literature, musicology, and information and communication science in its first three years. In fact, the majority of the members of the editorial board are, through their academic career and research, from two disciplines - literature or history of art and sociology, for example, or sociology and English, or philosophy and political science. The peer review process does not appear to favour one discipline over another. 
Fig. 6. Subject Disciplines of Authors of Unsolicited Articles

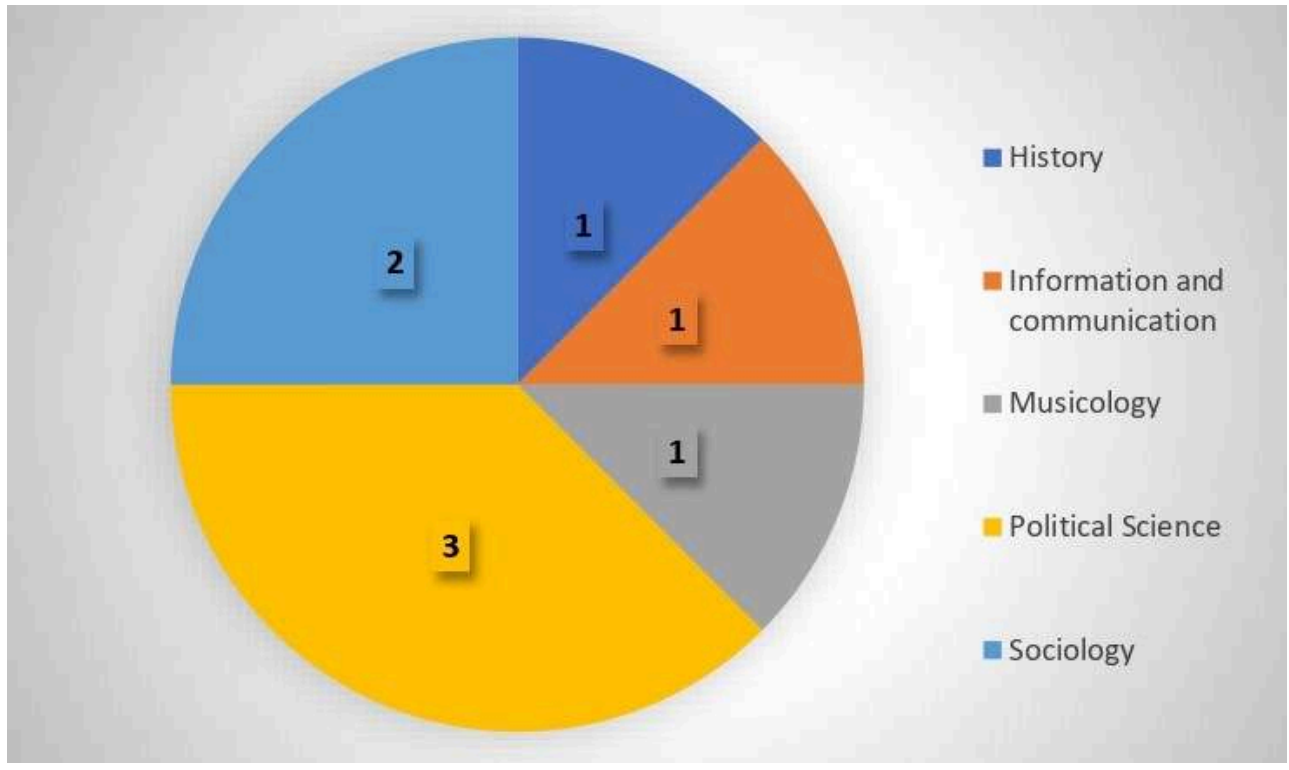

Values represent number of articles

Source: Julienne Flory for BS/SG

Since 2017, the journal has consistently received and published spontaneously submitted articles. This proves that Biens symboliques/Symbolic Goods has indeed taken root in the humanities and social science publishing world, which is something we are of course very happy about. We therefore take the opportunity of this special introduction to thank each and everyone of our authors for their trust in the journal and the sharing of their articles, of which we hope to publish many more in the years to come.

\section{BIBLIOGRAPHY}

ANGLARET Anne-Sophie \& SOFIo Séverine (2020). “Le Projet Transiens: s'appuyer sur l'expertise des traductrices et des traducteurs en SHS pour promouvoir la diffusion multilingue des revues scientifiques". Biens symboliques/Symbolic Goods post.

BoIs Géraldine \& THIBAULT Adrien (2018). "Sociologists in Themselves, Sociologists for Themselves. The Sociology of Art and Culture at Association française de sociologie Congresses (2004-2013)". Translated by Jean-Yves Bart. Biens symboliques/Symbolic Goods, 3.

Editorial board (2017). "Why Biens symboliques/Symbolic Goods?".Translated by Delaina Haslam. Biens symboliques/ Symbolic Goods, 1.

CONFINÉE LIBÉRÉE (2020). “Quand le confinement accrô̂t les inégalités de genre”, Université ouverte. 
DEVINEAU Sophie, COUVRY Camille, FÉLIU François, RENARD Anaïs (2018). "Working in Higher Education in France Today: A Specific Challenge for Women." International Journal of Higher Education, 7(3): 209-220.

GARNIER Lucy (2020). “Traduire les sciences humaines et sociales du français vers l'anglais. Enjeux, défis et apports." Biens symboliques/Symbolic Goods, 7.

\section{APPENDIXES}

- "First-read" form

First-Read Table

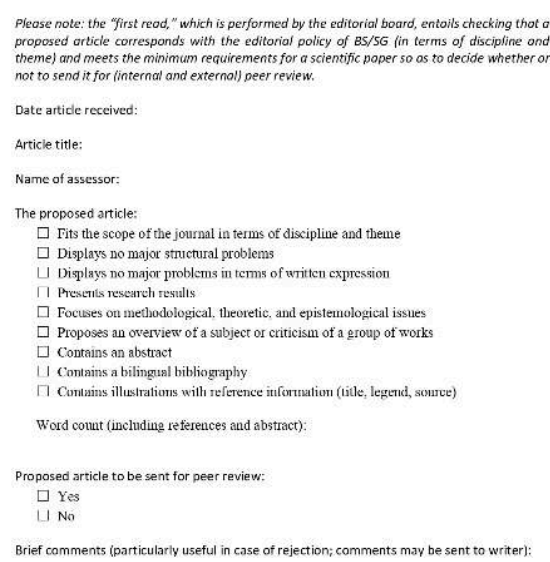

\section{NOTES}

1. The Committee on Publication Ethics is a forum that was founded in 1997 for publishers of peer reviewed journals to discuss all aspects of publication ethics. By joining COPE, members agree to adhere to a charter that sets out 16 principles of transparency and good practices in scientific publishing.

2. See the editorial of the first issue of the journal (Editorial Board 2017).

3. The editorial team would like to thank the sixty-one external experts who, from the end of 2016 to end-2020, have carried out essential work in order for the journal to function properly, and work that is essential for the publication of high-quality scientific productions.

4. In these examples, it should be explained that in France, école maternelle comprises classes of children from three to six years old; that the Brevet de technicien supérieur (BTS) is a short two-year qualification after the baccalauréat for students who have taken technology or vocational studies; and that the École normale supérieure (ENS) is a prestigious and extremely selective 
teaching establishment which is accessed via entrance exams to train school and university teachers and researchers.

5. "The Lang years" refers to the periods in which Jack Lang was minister of culture, between 1981 and 1986 and between 1988 and 1992.

6. The salaire minimum de croissance (Smic) is the French legal minimum hourly wage that an employee must receive.

7. Compagnies républicaines de sécurité (CRS) are the general reserve of the French National Police deployed most often on security missions and for crowd and riot control.

8. See Bois \& Thibault 2018.

9. Regarding what this specialization entails for translators, see Lucy Garnier 2020.

10. The journal also has a section entitled "Research in Translation" every other issue which gives the floor to translators themselves. The journal is also at the heart of the Transiens project, which promotes the practice of multilingual synthesis to compensate for the adverse effects of the domination of English language in social science. Translation is a key subject of debate for the BS/SG editorial board.

\section{AUTHORS}

\section{JULIENNE FLORY}

Biens symboliques/Symbolic Goods (BS/SG) 